\title{
Erratum
}

\section{Journal of Biosciences}

\author{
Volume 41, Number 2, June 2016, pp 283-294 \\ The autoregulatory loop: \\ A common mechanism of regulation of key sex determining genes in insects
}

\author{
Suresh Kumar Sawanth, Gajula Gopinath, Nagraj Sambrani and Kallare P Arunkumar
}

The following corrections are to be made in the printed version of the above article:

1. Page 287, section 3.1, line 48 from top: add Hediger et al. 2010:

"In females, forced splicing of tra is maintained throughout the life cycle by virtue of the autoregulatory loop (Jablonka and Lamb 1995; Gabrieli et al. 2010; Pane et al. 2002; Morrow et al. 2014)" should be read as "In females, forced splicing of tra is maintained throughout the life cycle by virtue of the autoregulatory loop (Jablonka and Lamb 1995; Gabrieli et al. 2010; Hediger et al. 2010; Pane et al. 2002; Morrow et al. 2014)".

2. Page 289, section 4, line 3 from top: 'suggests' to be read as 'demonstrates':

"The presence of TRA binding sites on pre-mRNA of Sxl suggests that TRA stimulates the SXL positive autoregulatory feedback loop" should read as "The presence of TRA binding sites on pre-mRNA of Sxl demonstrates that TRA stimulates the SXL positive autoregulatory feedback loop."

3. Page 289, section 4, line 6 from top: (Horabin 2005) to be read as (Siera and Cline 2008):

"This event is carried over to the other neighbouring germ cells non-autonomously by cell-to-cell interactions (Horabin 2005)" should read as "This event is carried over to the other neighbouring germ cells non-autonomously by cell-to-cell interactions (Siera and Cline 2008)."

\section{References}

Hediger M, Henggeler C, Meier N, Perez R, Saccone G and Bopp D et al. 2010 Molecular characterization of the key switch F provides a basis for understanding the rapid divergence of the sex-determining pathway in the housefly. Genetics 184 155-170 